\title{
Criopreservação de Ovócitos de Bovinos Imaturos Desnudados ou Não, Utilizando o Etilenoglicol pelo Método da Vitrificação ${ }^{1}$
}

\author{
Eduardo Paulino da Costa ${ }^{2}$, José Domingos Guimarães ${ }^{3}$, \\ Ciro Alexandre Alves Torres ${ }^{4}$, Letícia Martins Fagundes ${ }^{5}$, Marilú Martins Gioso ${ }^{5}$
}

RESUMO - Objetivou-se avaliar os efeitos da vitrificação em ovócitos de bovinos após o cultivo in vitro, utilizando o etilenoglicol como crioprotetor. Ovócitos obtidos de ovários de vacas abatidas em matadouro foram distribuídos aleatoriamente em três tratamentos. Tratamento 0 (testemunha): ovócitos não-desnudados e não-congelados. Tratamento 1: vitrificação de ovócitos imaturos não desnudados, desidratados previamente por cinco minutos em três soluções contendo 20,20 e $40 \%$ de etilenoglicol, acrescidas de 0,3 mol L ${ }^{-1}$ de trehalose e 20\% de PVP, em meio de Talp Hepes. Tratamento 2: vitrificação de ovócitos imaturos desnudados, conforme o Tratamento 1. Após o descongelamento (imersão em banho-maria a $30^{\circ} \mathrm{C}$ por 20 segundos), os ovócitos foram reidratados gradativamente, mantendo-os por 6 minutos em cada uma das soluções a seguir, sucessivamente: meio Talp Hepes com $20 \%$ de etilenoglicol $+0,3$ mol L $\mathrm{L}^{-1}$ de trehalose $+10 \%$ de PVP e meio Talp Hepes sem etilenoglicol, trehalose e PVP, onde foram lavados três vezes. Posteriormente, os ovócitos foram cultivados a $38,5^{\circ} \mathrm{C}$, com $95 \%$ de umidade e atmosfera de $5 \%$ de $\mathrm{CO}_{2}$ por 24 horas. Após o cultivo, os ovócitos foram fecundados e os embriões cultivados in vitro por sete dias. Foi encontrada uma taxa de maturação nuclear de $81(68 / 84), 19(7 / 36)$ e $0 \%(0 / 31)$, nos Tratamentos 0,1 e 2, respectivamente. As taxas de clivagem e de desenvolvimento embrionário foram de 56,4 (102/181) e 54,9\% (56/ 102), 1,7 (1/60) e $0,0 \%(1 / 60), 0,0(0 / 71)$ e $0,0 \%(0 / 71)$, nos Tratamentos 0,1 e 2 , respectivamente. Esses resultados indicam que o procedimento de vitrificação, segundo os protocolos utilizados, não é indicado para a criopreservação de ovócitos de bovinos.

Palavras-chave: ovócitos, bovinos, vitrificação

\section{Cryopreservation of Bovines Immature Oocytes Desnudes or not, by the Ethylene Glycol Vitrification Method}

\begin{abstract}
The objective was to evaluate the effects of vitrification of immature bovine oocytes after in vitro culture, by the use of cryoprotectors ethylene glycol. Oocytes from cows ovaries from slaughters houses were randomly alocated into three treatments. Treatment 0 (control): frozen-thawed undesnude oocytes; treatment 1, immature vitrificated undesnude oocytes dehydrated for 5 minutes in each of the following solutions of 20, 20 and $40 \%$ of ethylene glycol, respectively, associated to $0.3 \mathrm{Mol}^{-1}$ of trehalose and $20 \%$ of PVP, in media Talp Hepes, and, treatment 2, the same as treatment 1, but desnudes oocytes. After frozen-thawed of the oocytes (imersion in water bath at $30^{\circ} \mathrm{C}$ for 20 seconds), the oocytes were gradually rehydrated, in the following sequence of solutions: media Talp Hepes with $20 \%$ of ethylene glycol $+0.3 \mathrm{Moll}^{-1}$ of trehalose $+10 \%$ of PVP and media Talp Hepes without ethylene glycol, trehalose and PVP, were washed three times. Ultimately, the oocytes were cultured at $38.5^{\circ} \mathrm{C}$, with $95 \%$ umidity and atmosphere of $5 \%$ of $\mathrm{CO}_{2}$ for 24 hours. After culture, the oocytes were fertilized and the embryos cultured in vitro for seven days. The nuclear maturation were $81(68 / 84), 19(7 / 36)$ and $0 \%(0 / 31)$, for treatments 0,1 and 2, respectively. The cleavage and development rates were: $56.4(102 / 181)$ and $54,9 \%(56 / 102), 1,7 .(1 / 60)$ and $0,0 \%(1 / 60), 0,0(0 / 71)$ and $0,0 \%(0 / 71)$, for the treatments 1,2 e 3 , respectively. These results show that the vitrification procedures, by the used protocols, are not indicated for bovine oocytes cryopreservation.
\end{abstract}

Key Words: oocytes, bovine, vitrification

\section{Introdução}

A eficiência da produção animal é dependente dos processos reprodutivos inerentes ao macho e à fêmea. Tal condição levou Couter (1986) a preconizar que, economicamente, a eficiência reprodutiva é cinco ou 10 vezes mais importante do que o desempenho no desenvolvimento ponderal ou na qualidade do produto, respectivamente. Desse modo, justificam-se estudos visando desenvolver e aprimorar biotecnologias que possibilitem aumentar a eficiência reprodutiva. Além da inseminação artificial e da transferência de embriões, outras biotecnologias encontram-se em processo de im-

\footnotetext{
${ }^{1}$ Apoio financeiro da FAPEMIG.

2 Professor Adjunto - Universidade Federal de Viçosa - Departamento de Veterinária. E.mail: epcosta@ufv.br

3 Professor Adjunto - Universidade Federal de Viçosa. E.mail: jdguima@ufv.br

4 Professor Titular - Universidade Federal de Viçosa. E.mail: ctorres@ufv.br

5 Mestranda em Medicina Veterinária - Universidade Federal de Viçosa.
} 
plantação, destacando-se, nesse contexto, a fecundação in vitro (FIV).

A vida fértil relativamente curta dos ovócitos de bovinos é um fator limitante na implementação de muitos procedimentos in vitro. Desse modo, figuram como imprescindíveis os procedimentos de congelamento de gametas femininos, visando à preservação de genótipos de valor, assim como a utilização dos mesmos em biotecnologias afins. Entretanto, a criopreservação de ovócitos ainda não apresenta resultados satisfatórios que justifiquem seu emprego como técnica economicamente viável.

Ainda não está definido qual é o estágio de maturação do ovócito mais adequado para o congelamento. Como o desenvolvimento do fuso corresponde ao momento da ruptura do envelope nuclear, tem sido relatado que o congelamento de ovócitos imaturos antes dessa fase poderia evitar danos ao fuso (Friedler et al., 1988; Van Blerkom, 1989). Entretanto, o congelamento de ovócitos imaturos, da mesma forma que os maturados, provoca aumento nos índices de poliploidia e diminuição dos índices de fecundação, em comparação com o grupo-controle (Friedler et al., 1988; Mikich et al., 1988; Hernandez-Ledezma \& Wright, 1989; Le Gal e Massip, 1999). Adicionalmente, sofrem mais danos estruturais do que os ovócitos maturados, quando expostos aos crioprotetores (Herrker et al., 1991; Yang et al., 1994; Luvoni \& Pellizzari, 2000). Essas observações são corroboradas por Yang et al. (2000), os quais encontraram resultados negativos ao congelar ovócitos imaturos. Entretanto, alguns pesquisadores obtiveram melhores resultados quando vitrificaram ovócitos imaturos (Arav et al., 1993; Kuchenmeister \& Kuwayama, 1997). Le Gal \& Massip (1999) vitrificando ovócitos bovinos imaturos e maturados, não constataram diferenças na taxa de fecundação, a qual foi de 38,3 e $36,7 \%$, respectivamente. Esses diferentes resultados encontrados na literatura indicam que existem outros aspectos ainda não definidos, e que devem ser considerados, como o tipo e concentração de crioprotetor, além de outros detalhes relacionados aos procedimentos de desidratação e resfriamento

Um aspecto a ser considerado na criopreservação de ovócitos imaturos é a falta de sincronia entre a maturação nuclear e a citoplasmática, fato este verificado por Hurtt et al. (2000) e Luvoni \& Pellizzari (2000). É bem conhecido que o desenvolvimento embrionário é fortemente dependente da adequada maturação citoplasmática, ressaltando-se que os danos nas estruturas do citoplasma induzidos pela baixa temperatura podem explicar os resultados pouco promissores ainda obtidos no congelamento de ovócitos bovinos (Van Der et al., 1992). Entretanto, quanto aos ovócitos já maturados, as condições de resfriamento e exposição das células aos crioprotetores podem induzir a uma instabilidade dos fusos meióticos, provocando segregação anormal dos cromossomos no reinício da meiose durante a fecundação (Pickering \& Johnson, 1987; Shaw et al., 2000).

A variação nos resultados de clivagem obtidos após o congelamento de ovócitos de bovinos pelo método clássico com diferentes crioprotetores vai de zero (Watanabe \& Oliveira Filho, 1992) até 54\% (Lim et al., 1999), enquanto pela vitrificação esses resultados variam de zero (Bem et al., 1992) até 74\% (Arav et al., 2000). Segundo Vajta (2000a), existem diferenças consideráveis nos tipos de danos que podem ocorrer durante o congelamento clássico e a vitrificação. A formação de gelo ocorre no método clássico, mas é quase ausente na vitrificação. Além disso, os ovócitos passam rapidamente pelos intervalos mais críticos de temperatura na vitrificação, embora, lesões estruturais possam ocorrer em ambos os processos. Em trabalhos recentes, tem-se considerado a vitrificação um procedimento promissor para a criopreservação de ovócitos e embriões bovinos. Os maiores desafios para os pesquisadores seriam melhorar e estabilizar os resultados e, ainda, estabelecer um protocolo de vitrificação aplicável em diferentes estágios de desenvolvimento do ovócito (Vajta, 2000b).

A vitrificação requer soluções crioprotetoras em concentrações extremamente elevadas. No esforço para diminuir a toxidade dos crioprotetores, várias soluções crioprotetoras e técnicas foram introduzidas (Shaw et al., 2000). Características comuns nesses métodos foram o uso de crioprotetores menos tóxicos, e a combinação de dois ou mais crioprotetores, dos quais pelo menos um deve ser permeável, sendo o EG utilizado com tal propósito (Vatja, 2000b). Segundo Kasai et al. (1990), o EG pode ter vantagens sobre os outros crioprotetores devido à sua baixa toxicidade. Esses mesmos autores explicaram que, devido ao baixo peso molecular do EG em relação ao DMSO, glicerol (G) e $\mathrm{PROH}$, há maior permeação das células durante curto período de exposição e, conseqüentemente, rápido efluxo após o aquecimento, prevenindo a ocorrência das injúrias celulares de origens tóxica e osmótica.

Suzuki et al. (1996), congelando ovócitos imaturos de bovinos em solução que continha polivinilpirrolidona

R. Bras. Zootec., v.31, n.3, p.1122-1129, 2002 
(PVP) e trehalose (T), obtiveram $80 \%$ de desenvolvimento até a metáfase II. Martino et al. (1996) congelaram ovócitos bovinos pelo método rápido, utilizando EG e sacarose. Obtiveram ainda um total de $34 \%$ de ovócitos morfologicamente normais e 3\% de taxa de clivagem, ressaltando-se que, destes, somente $1 \%$ desenvolveu-se até blastocisto. Recentemente, Yang et al. (2000) utilizaram o PVP acrescido à solução de vitrificação de ovócitos bovinos em estágio de vesícula germinativa. Estes pesquisadores encontraram baixas encontraram baixas taxas de maturação e de clivagem.

A concentração necessária de crioprotetores para realização da vitrificação é muito alta, podendo provocar efeitos tóxicos aos ovócitos (Niemann, 1991). Da mesma forma, a duração do tempo de equilíbrio em que os ovócitos são expostos aos crioprotetores também é de importância crítica. Entretanto, Luna et al. (2000) submeteram ovócitos bovinos em diferentes estágios de maturação por $0,8,12$ e 22 horas em contato com a solução de vitrificação, encontrando uma freqüência de aneuploidia de 3/17,5/21,3/16 e 1/16, respectivamente. Os resultados evidenciam que a exposição à solução crioprotetora utilizada em diferentes tempos de maturação, não altera a freqüência de aneuplodias.

Além da concentração e tempo de exposição aos crioprotetores, a toxicidade de um crioprotetor também está relacionada à temperatura (Kasai et al., 1990). A exposição de ovócitos maturados in vitro de bovinos a $4^{\circ} \mathrm{C}$ provoca completo desarranjo dos fusos. Após o reaquecimento a $39^{\circ} \mathrm{C}$, não há o retorno da morfologia normal dos fusos (Amam \& Parks, 1994).

Várias taxas de resfriamento tem sido estudadas, com o intuito de acelerar a passagem pelo intervalo de temperatura mais crítica, entre +15 e $-5^{\circ} \mathrm{C}$, minimizando os danos por resfriamento. Neste contexto, Arav et al. (2000) obtiveram resultados excelentes de desenvolvimento embrionário após vitrificar ovócitos de bovinos em nitrogênio líquido mantido em ambiente de vácuo.

O objetivo deste trabalho foi avaliar os efeitos da vitrificação sobre a capacidade de desenvolvimento após o cultivo in vitro de ovócitos, utilizando-se o etilenoglicol associado com outros crioprotetores, além de verificar se a presença ou não de cumulus oophorus interfere no congelamento, visando obter ovócitos de melhor qualidade após a desvitrificação e o cultivo in vitro.

R. Bras. Zootec., v.31, n.3, p.1122-1129, 2002

\section{Material e Métodos}

Foram utilizados ovários de vacas abatidas em matadouro. Imediatamente após o abate e a evisceração, os ovários foram removidos e imersos em solução fisiológica a $35^{\circ} \mathrm{C}$, acrescida de penicilina e estreptomicina (Sirard \& Bilodeau, 1990).

Após a coleta, foram levados ao laboratório e lavados três vezes em solução fisiológica a $35^{\circ} \mathrm{C}$. A aspiração, manipulação e classificação dos ovócitos foram realizadas conforme descrito por Costa et al. (1997c), selecionando-se os ovócitos que apresentavam cumulus compactos.

Após a classificação e seleção, metade dos ovócitos foi desnudada segundo Costa et al. (1997a). Posteriormente, os ovócitos foram submetidos aos tratamentos, conforme descrito a seguir:

Tratamento-testemunha (T 0): ovócitos não-desnudados e não-congelados. Esses ovócitos foram submetidos aos procedimentos de cultivo e fecundação in vitro, conforme descritos em itens posteriores.

Tratamento 1 ( $\mathrm{T}$ 1): congelamento através da vitrificação de ovócitos imaturos não-desnudados, utilizando-se como crioprotetor o etilenoglicol, associado à trehalose e polivinilpirrolidona (PVP). O meio-base utilizado para a desidratação (e também para a reidratação após o descongelamento) foi o Talp Hepes, preparado conforme Costa (1994), sem soro fetal bovino, acrescido de $0,4 \%$ de albumina sérica bovina (BSA) e ajustado para $285 \mathrm{Mosm} / \mathrm{kg}$ (denominado meio-base).

A desidratação e a vitrificação foram realizadas conforme os procedimentos utilizados em zigotos por Saha et al. (1996), com a solução de vitrificação constituída de $40 \%$ de $\mathrm{EG}+0,3 \mathrm{~mol} \mathrm{l}^{-1}$ de trehalose e $20 \%$ de PVP.

Tratamento 2 ( ( 2 ): congelamento através da vitrificação de ovócitos imaturos desnudados, utilizando-se como crioprotetor o etilenoglicol, associado à trehalose e polivinil-pirrolidona (PVP). Foram utilizados os mesmos procedimentos descritos no Tratamento 1 .

Os ovócitos dos tratamentos 1 e 2 foram descongelados através da imersão em banho-maria a $30^{\circ} \mathrm{C}$, por 20 segundos. Após o descongelamento, os ovócitos foram reidratados gradativamente, mantendo-os por seis minutos em cada uma das soluções a seguir, sucessivamente: meio-base com $20 \%$ de etilenoglicol $+0,3 \mathrm{~mol} \mathrm{l}^{-1}$ de trehalose $+10 \%$ de PVP e meio-base sem etilenoglicol, trehalose e PVP, onde foram lava- 
dos três vezes. Posteriormente, os ovócitos de todos os tratamentos foram submetidos ao cultivo para maturação in vitro, co-cultivados com células da granulosa em suspensão. O cultivo foi realizado com Meio TCM modificado de acordo com Costa (1994). Os cultivos foram em placas de Petri de $35 \mathrm{~mm}$ de diâmetro, contendo $4 \mathrm{~mL}$ de meio de cultivo previamente equilibrado durante uma hora a $39^{\circ} \mathrm{C}$, em atmosfera de $5 \%$ de $\mathrm{CO}_{2}, 95 \%$ de ar atmosférico e $100 \%$ de umidade. Após 24 horas de cultivo, os ovócitos foram submetidos aos procedimentos para avaliação da taxa de maturação.

Para avaliação da maturação nuclear, foram utilizados 30 ovócitos de cada tratamento após 24 horas de incubação. Os ovócitos não-desnudados foram submetidos aos procedimentos de remoção do cumulus oophorus, segundo Costa et al. (1997a), hipotonizados e submetidos aos procedimentos para avaliação do estágio de maturação (Costa et al., 1997b). Foi considerado maduro, em nível nuclear, o ovócito que apresentasse configuração cromossômica em metáfase II e também o grupo cromossômico pertencente ao primeiro corpúsculo polar, quando este estivesse presente.

A fecundação in vitro foi realizada utilizando sêmen bovino congelado em palhetas médias $(0,56 \mathrm{~mL})$ na concentração de 2 x 107 espermatozóides móveis por dose, adotando-se procedimentos segundo Costa (1994). Após 18 horas de incubação, os zigotos foram cocultivados em monocamada de células da tuba uterina, durante sete dias, em meio de TCM acrescido de substâncias (Costa, 1994) a $39^{\circ} \mathrm{C}$, em atmosfera de 5\% de $\mathrm{CO}_{2}, 95 \%$ de ar atmosférico e $100 \%$ de umidade. $\mathrm{O}$ meio de cultura foi renovado a cada dois dias.

A taxa de clivagem foi avaliada no terceiro dia de cultivo. No sétimo dia, foi verificada a taxa de mórulas e de blastocistos.

Os dados obtidos de cada amostragem foram analisados pelo teste do qui-quadrado, com relação às taxas de maturação nuclear, de fecundação e de clivagem (Gomes, 1977).

\section{Resultados e Discussão}

Na Tabela 1, pode-se observar que houve diferenças entre os três tratamentos quanto à habilidade de maturar. Os resultados de clivagem e desenvolvimento de ovócitos submetidos à fecundação in vitro estão apresentados nas Tabelas 2 e 3, respectivamente. Os ovócitos vitrificados ficaram comprome-
Tabela 1 - Maturação nuclear de ovócitos submetidos ao cultivo in vitro de ovócitos nãocriopreservados (TO) ou submetidos à vitrificação prévia (T1 e T2)

Table 1 - Oocytes nuclear maturation submitted to in vitro culture, not cryopreserved (TO), or submitted to a previous vitrification (T1 and T2)

\begin{tabular}{|c|c|c|}
\hline & \multicolumn{2}{|c|}{$\begin{array}{c}\text { Tratamento } \\
\text { Treatment }\end{array}$} \\
\hline & $\begin{array}{c}\text { Ovócitos } \\
\text { avaliados (n) } \\
\text { Oocytes } \\
\text { evaluated (n) }\end{array}$ & $\begin{array}{c}\text { Maturação } \\
\text { nuclear (\%) } \\
\text { Nuclear } \\
\text { maturation (\%) }\end{array}$ \\
\hline $\begin{array}{l}\text { T0 (testemunha) } \\
\text { T0 (control) }\end{array}$ & 84 & $68(81,0)$ \\
\hline $\begin{array}{l}\text { T1 (vitrificados) } \\
\text { T1 (vitrificated) }\end{array}$ & 36 & $7(19,0)$ \\
\hline $\begin{array}{l}\text { T2 (desnudados vitrificados } \\
\text { T2 (vitrificated desnudes) }\end{array}$ & os) 31 & $0(00,0)$ \\
\hline
\end{tabular}

tidos quanto à habilidade de maturar e desenvolver-se após a fecundação. Tais resultados indicam que os procedimentos utilizados para vitrificação danificaram seriamente os ovócitos

A taxa de maturação in vitro do grupo-controle (81\%), encontrada neste experimento, foi semelhante à obtida por vários pesquisadores, com ligeiras diferenças, as quais poderiam ser atribuídas, provavelmente, às particularidades dos meios de maturação ou a qualidade geral dos ovócitos obtidos em função da época do ano em que foram coletados $(91,84,71$, 67, 67 e 87\% encontrados por Costa (1994), Camargo (1995), Le Gal et al. (1999), Dhali et al. (2000a), Dhali et al. (2000b) e Yang et al. (2000), respectivamente). Os resultados evidenciam que os procedimentos e meios adotados para a maturação in vitro dos ovócitos foram adequados.

Os ovócitos vitrificados previamente apresentaram taxas de maturação de 19 e $0 \%$ para os nãodesnudados e desnudados, respectivamente. Esses resultados indicam que os crioprotetores ou os procedimentos utilizados não foram eficazes na preservação da integridade do ovócito. Também estão de acordo com os achados de Yang et al. (2000), os quais não encontraram eficiência da vitrificação de ovócitos bovinos utilizando a polivinilpirrolidona como crioprotetor.

Neste experimento, apesar de ter ocorrido expansão das células do cumulus em todos os ovócitos vitrificados após o cultivo in vitro, foi verificado baixa taxa de maturação $(19 \%)$ ou nula $(0 \%)$ (Tabela 1 , 
Tratamentos 1 e 2). Condição semelhante foi observada por Yang et al. (1994), os quais encontraram $60 \%$ de expansão das células do cumulus, mas apenas $8,3 \%$ maturaram in vitro. É provável que as células do cumulus sejam mais resistentes à criopreservação, em função de seu menor volume, o que possibilitaria melhor difusão dos crioprotetores. Diante disso, a mucificação ocorreria normalmente, independentemente da condição do ovócito. Hurt et al. (2000) cultivaram ovócitos bovinos previamente vitrificados, verificando também expansão das células do cumulus. Esses pesquisadores obtiveram taxa de maturação nuclear de $65 \%$. Entretanto, verificaram que as células do cumulus se desprendiam com muita facilidade, fato também verificado no presente experimento. Essa condição poderia indicar danos nas junções gap entre as células do cumulus e o ovócito.

A taxa de maturação in vitro obtida por Dhali et al. (2000a) com a vitrificação de ovócitos imaturos com células do cumulus foi ligeiramente superior à do presente experimento. Esses pesquisadores, submetendo os ovócitos aos crioprotetores por um ou três minutos, obtiveram taxas de maturação de $21,5 \mathrm{e}$ $31,5 \%$, respectivamente. É provável que o tempo de desidratação de três minutos tenha provocado menos alterações indesejáveis nos ovócitos, possibilitando melhores resultados de maturação. Segundo Otoi et al. (1998), a desidratação é de grande valia para o sucesso da vitrificação, existindo diferença significativa na taxa de clivagem, quando é aumentado o número de etapas na desidratação antes da criopreservação. No presente experimento, foram utilizados somente ovócitos com cumulus compactos, uma vez que são os que apresentam maiores possibilidades de desenvolvimento pós-fecundação (Madison et al., 1992, Chian et al., 1994). As células do cumulus poderiam dificultar a entrada e saída de crioprotetores, afetando, assim, a qualidade dos mesmos. Adicionalmente, o tempo de exposição ao crioprotetor utilizado foi de cinco minutos, com concentrações de crioprotetores inferiores às utilizadas por Dhali et al. (2000a) e Dhali et al. (2000b). Tentativas de desnudamento parcial dos ovócitos, visando à melhor penetração dos crioprotetores, foram evidenciadas por Otoi et al. (1998). Entretanto, Vajta (2000b) comentou que é muito difícil realizar a remoção parcial das células do cumulus de forma uniforme em um grupo de ovócitos, o que pode, então, resultar em penetração desigual do crioprotetor.

Apesar dessas considerações em relação à possibilidade de maior eficiência de penetração dos crioprotetores em ovócitos com poucas células do cumulus, é provável que este não seja o fator principal, uma vez que não houve maturação nuclear nos ovócitos desnudados e submetidos aos mesmos procedimentos ( $0 \%$ de maturação). Diante disso, assumem caráter de importância no sucesso da vitrificação os tipos e concentração de crioprotetores, assim como o tempo de exposição dos ovócitos aos mesmos.

A taxa de maturação dos ovócitos com cumulus foi semelhante à encontrada por Le Gal et al. (1999). Estes autores afirmaram que o tempo de exposição aos crioprotetores não afeta a taxa de maturação, ressaltando que os principais danos causados aos ovócitos vitrificados ainda imaturos seriam as injúrias provocadas pelo congelamento. Entretanto, esses autores obtiveram $16,3 \%$ de clivagem, resultado esse superiore ao obtido no presente experimento (Tabela 2). É provável que o número de banhos e o tipo de substância utilizada na reidratação possam ter influenciado os resultados. No presente experimento os ovócitos foram reidratados com apenas um banho, enquanto Le Gal et al. (1999) reidrataram com três

Tabela 2 - Taxa de clivagem de ovócitos submetidos à fecundação in vitro após a maturação (T0) ou vitrificação prévia e maturação (T1 e T2 )

Table 2 - Cleavage from oocytes submitted to a fertilization in vitro after maturation (TO), or maturated after previous vitrification (T1 and T2)

\begin{tabular}{lccc}
\hline $\begin{array}{l}\text { Tratamento } \\
\text { Treatment }\end{array}$ & Total de ovócitos cultivados & $\begin{array}{c}\text { Clivados } \\
\text { Cleavage }\end{array}$ & Porcentagem \\
\hline T0 (testemunha) & 181 & 102 & 56,4 \\
$T 0$ (control) & 60 & 1 & 1,7 \\
T1 (não-desnudados vitrificados) & & 0 & 0,0 \\
$T 1$ (undesnudes vitrificated) & 71 & 0 \\
T2 (desnudados vitrificados) & & & \\
$T 2$ (desnudes vitrificated) & & \\
\hline
\end{tabular}


Tabela 3- Desenvolvimento embrionário de ovócitos submetidos à fecundação in vitro após a maturação (T0) ou vitrificação prévia e maturação (T1 e T2 )

Table 3 - Embryo development from oocytes submitted to a fertilization in vitro after maturation (TO), or maturated after previous vitrification ( $T 1$ and $T 2)$

\begin{tabular}{lccc}
\hline $\begin{array}{l}\text { Tratamento } \\
\text { Treatment }\end{array}$ & Cultivados & $\begin{array}{c}\text { Mórulas e blastocistos } \\
\text { Morulae and blastocysts }\end{array}$ & Porcentagem \\
\hline T0 (testemunha) & 102 & 56 & 54,9 \\
T0 (control) & 60 & 0 & 0,0 \\
T1 (não-desnudados vitrificados) & & 0 & 0,0 \\
$\begin{array}{l}\text { T1 (undesnudes vitrificated) } \\
\text { T2 (desnudados vitrificados) }\end{array}$ & 71 & & \\
$T 2$ (desnudes vitrificated) & & &
\end{tabular}

banhos, utilizando concentrações decrescentes de galactose. Analisando esse aspecto, o único banho a que foram submetidos os ovócitos poderia ter sido insuficiente para a retirada do crioprotetor do meio intracelular, comprometendo a integridade ovocitária. Entretanto, Saalfeld et al. (1997) obtiveram resultados de clivagem $(1,4 \%)$ inferiores ao deste experimento, utilizando quatro banhos para a reidratação de ovócitos vitrificados com EG. Apesar disso, esses autores desidrataram os ovócitos durante somente 30 segundos. Pode ser que o curto tempo de exposição utilizado na desidratação teria insuficiente, acarretando, assim, problemas subseqüentes. Já em outros experimentos utilizando COC maturados in vitro banhados apenas uma ou três vezes para reidratação, obtiveram-se melhores resultados de fecundação in vitro (Otoi et al., 1993; Arav et al., 2000). Bem et al. (1993), utilizando quatro banhos para reidratação, conseguiram $43,5 \%$ de taxa de maturação. Entretanto, eles avaliaram a maturação nuclear somente nos ovócitos considerados com morfologia viável, enquanto no presente experimento foram utilizados ovócitos de maneira aleatória, sem levar em conta a morfologia dos mesmos. O que fica evidente é que ainda não foi definido um procedimento-padrão que possibilite resultados práticos e, principalmente, com repetibilidade.

Apenas um ovócito $(1,7 \%)$ no Tratamento 1 do presente experimento clivou (Tabela 2). Esse resultado indica que, embora tenha ocorrido $19 \%$ de maturação nuclear, os procedimentos de vitrificação provocaram outras alterações que comprometeram, de alguma forma, a integridade celular, interferindo, provavelmente, na maturação citoplasmática. Acredita-se que essa alteração seja em nível de grânulos corticais, pois estes são de fundamental importância para o sucesso da fecundação.

Adicionalmente, não houve desenvolvimento embrionário para mórulas e blastocistos dos ovócitos vitrificados (Tabela 3). Hurt et al. (2000) verificaram que a vitrificação provocava migração prematura dos grânulos corticais durante a maturação in vitro, caracterizando deficiência na maturação citoplasmática dos ovócitos. Essa migração prematura dos grânulos corticais levaria, também, a um endurecimento prematuro da zona pelúcida (Vicent et al., 1990) e à conseqüente redução da taxa de fecundação. Outro problema, de acordo com Fabbri et al. (1998), é a diminuição do número de grânulos corticais que podem comprometer a reação da zona pelúcida, permitindo a penetração de vários espermatozóides.

Os valores obtidos no presente experimento, referentes à vitrificação de ovócitos desnudos (Tabela 1), indicam que as células do cumulus têm a função de fornecer nutrientes essenciais ao ovócito em todos os estágios de seu desenvolvimento, conforme relatado por Thibault et al. (1987). Os resultados encontrados no experimento em questão foram inferiores aos de Bem et al. (1993), Im et al. (1997) e Fabbri et al. (1998), utilizando o método clássico, indicando que este método é mais eficiente do que a vitrificação para ovócitos bovinos previamente desnudados. A ausência das células do cumulus pode ter possibilitado a entrada de agentes crioprotetores de maneira mais intensa nos ovócitos, acarretando efeitos tóxicos nestes. Diante disso, é provável que os ovócitos desnudos necessitem de menor tempo de desidratação do que o utilizado no presente experimento. 


\section{Conclusões}

A associação de etilenoglicol, trehalose e polivinilpirrolidona não foi eficaz para a crioproteção de ovócitos imaturos bovinos, desnudos ou não, pela técnica da vitrificação.

A criopreservação de ovócitos imaturos de bovinos pelo método da vitrificação necessita ser mais estudada, em seus diversos aspectos e fases, tendo em vista os resultados inconsistentes na literatura, inclusive neste trabalho.

\section{Agradecimento}

À FAPEMIG, pelo apoio financeiro durante a execução deste experimento.

\section{Literatura Citada}

AMAN, R.R.; PARKS, J.E. Effects of cooling and rewarming on the meiotic spindle and chromosomes of in vitromatured bovine oocytes. Biology of Reproduction, v.50, p.203-110, 1994.

ARAV, A.; ZERON, Y.; OCHERETNY, A.A. New device and method for vitrification increases the cooling rate and allows successful cryopreservation of bovine oocytes. Theriogenology, v.53, n.1, p.248, 2000.

ARAV, A.; SHEHU, D.; MATTIOLI, M. Osmotic and cytotoxic study of vitrification of immature bovine oocytes. Journal of Reproduction and Fertility, v.99, p.353-358, 1993.

BEM, A.R.; FREITAS, V.C.; SOUSA, R.V. et al. Criopreservação de ovócitos imaturos bovinos utilizando como crioprotetor o propanediol. In: REUNIÃO ANUAL DA SOCIEDADE BRASILEIRA DE TRANSFERÊNCIA DE EMBRIÕES, 7, 1992, Jaboticabal. Anais... Jaboticabal: 1992. p.94.

BEM, A.R.; FREITAS, V.C.; SOUSA, R.V. et al. Criopreservation of immature oocyte of bovine using 1,2 propanediol and glycerol as cryoprotector. In: RÉUNION ASSOCIATION EUROPEENNE DE TRANSFERT EMBRYONNAIRE, 9., 1993, Lyon. Anais... Lyon: 1993. p.184.

CAMARGO, L.S. Criopreservação de ovócitos imaturos de bovinos com 1,2 propanediol. Itaguaí: Universidade Federal Rural do Rio de Janeiro, 1995. 62p. Dissertação (Mestrado em Medicina Veterinária) - Universidade Federal Rural do Rio de Janeiro, 1995.

CHIAN, R.C.; NIWA, K.; SIRARD, M.A. Effects of cumulus cells on male pronuclear formation and subsequent early development of bovine oocytes in vitro. Theriogenology, v.41, p.1499-1508, 1994.

COSTA, E.P. Aspectos morfológicos (citológicos e ultraestruturais) e desenvolvimento de ovócitos de bovinos "in vitro". Belo Horizonte: Universidade Federal de Minas Gerais, 1994. 155p. Tese (Doutorado em Ciência Animal) Universidade Federal de Minas Gerais, 1994.

COSTA, E.P.; VALE FILHO, V.R.; NOGEIRA, J.C. et al. Técnica simplificada para o desnudamento rápido de ovócitos de bovinos. Arquivo Brasileiro de Medicina Veterinária e Zootecnia, v.49, n.4, p.425-432, 1997a.
COSTA, E.P.; VALE FILHO, V.R.; NOGUEIRA, J.C. et al. Técnica para a avaliação do estádio de maturação nuclear de ovócitos bovinos cultivados "in vitro". Arquivo Brasileiro de Medicina Veterinária e Zootecnia, v.49, n.4, p.433440, $1997 b$.

COSTA, E.P.; VALE FILHO, V.R.; NOGUEIRA, J.C. et al. Tipos morfológicos de ocvócitos de bovinos. Arquivo Brasileiro de Medicina Veterinária e Zootecnia, v.49, n.4, p.417-424, 1997c.

COUTER, G.H. Puberty and postpuberal development of beef bulls. In: MORROW, D.A. (Ed.) Current therapy in theriogenology. Philadelphia: Saunders company, 1986. p. 142-148.

DHALI, A.; MANIK, R.S.; DAS, S.K. et al. Post-vitrification survival and in vitro maturation rate of buffalo (Bubalus bubalis) oocytes: effect of ethylene glycol concentration and exposure time. Animal Reproduction Science, v.63, p.159$165,2000 b$.

DHALI, A.; MANIK, R.S.; DAS, S.K. et al. Vitrification of buffalo (Bubalus bubalis) oocytes. Theriogenology, v.53, p.1295-1303, 2000a.

FABBRI, R.; PORCUS, E.; MARSELLA, T. et al. 1998. Oocyte cryopreservation. Human Reproduction, v.13, p.98-108, 1998.

FRIEDLER, S.; GINDICE, L.C.; LAMB, E.J. Criopreservation of embryos and ova. Fertility and Sterility, v.49, n.5, p.743-764, 1988.

GOMES, F.P. Curso de estatística experimental. 7.ed. Piracicaba: Nobel, 1977. 430p.

HERNANDEZ-LEDEZMA, J.J.; WRIGHT Jr., R.W. Deep freezing of mouse one cell embryos and oocytes using different cryoprotectants. Theriogenology, v.32, n.5, p.735743, 1989.

HERRLER, A.; RATH, D.; NIEMANN, H. Effects of cryoprotectants on fertilization and cleavage of bovine oocytes in vitro. Theriogenology, v.35, p.212, 1991.

HURTT, A.E.; LANDIM-ALVARENGA, F.; SEIDEL, G.E. et al. Vitrification of immature and mature equine and bovine oocytes in an ethylene glycol, ficoll and sucrose solution using open-pulled straws. Theriogenology, v.54, p.119128, 2000.

IM, K.S.; KANG, J.K.; KIM, H.S. Effects of cumulus cells, differents cryoprotectants, various maturation stages and preincubation before insemination on developmental capacity of frozen-thawed bovine oocytes. Theriogenology, v.47, p.881-891, 1997.

KASAI, M.; KOMI, J.H.; TAKAKAMO, A. et al. A simple method for mouse embryo cryopreservation in a low toxicity vitrification solution without appreciable loss viability. Journal Reproduction and Fertility, v.89, p.91-97, 1990.

KUCHENIMEISTER, U.; KUWAYAMA, M. In vitro blastocyst formation after vitrification of immature bovine oocytes. Theriogenology, v.47, p.348, 1997.

LE GAL, F.; MASSIP, A. Cryopreservation of cattle oocytes: Effects of meiotic stage, cycloheximide treatment, and vitrification procedure. Cryobiology, v.38, p.290-300, 1999.

LIM, J.M.; KO, J.J.; HWANG, W.S. et al. Development of in vitro matured bovine oocytes after cryopreservation with different cryoprotectants. Theriogenology, v.5, p.1303$1310,1999$.

LUNA, H.S.; FERRARI, I.; CARMO, T.F.M. et al. Efeito de uma solução de vitrificação aplicada em diferentes tempos de maturação sobre a taxa de aneuploidia em ovócitos bovinos.

R. Bras. Zootec., v.31, n.3, p.1122-1129, 2002 
In: SOCIEDADE BRASILEIRA DE TECNOLOGIA EM EMBRIÕES, 4., 2000, Caldas Novas. Anais... Caldas Novas: 2000 . p.200.

LUVONI, G.C.; PELLIZZARI, P. Embryo development in vitro of cat oocytes cryopreserved at different maturation stages. Theriogenology, v.53, p.1529-1540, 2000.

MADISON, V.; AVERY, B.; GREVE, T. Selection of imature bovine oocytes for developmental potential in vitro. Animal Reproduction Science, v.27, p.1-11, 1992.

MARTINO, A.; SONGSASEN, N.; LEIBO, S.P. Development into blastocysts of bovine oocytes cryopreserved by ultrarapid cooling. Biology of Reproduction, v.54, p.1059-1069, 1996.

MIKICH, A.B.; WOOD, M.J.; WHITTINGHAM, D.C. Efeitos da criopreservação sobre a morfologia e ultraestrutura de oócitos de Mus musculus: estudo preliminar. Revista do Centro de Ciência Rurais, v.18, p.54, 1988.

NIEMANN, H. Cryopreservation of ova and embryos from livestock: current status and research needs. Theriogenology, v.35, p.109-124, 1991.

OTOI, T.; TACHIKAVA, S.; KONDO, S. et al. Developmental capacity of bovine oocytes frozen in different cryoprotectants. Theriogenology, v.40, p.801-807, 1993.

OTOI, T.; YAMAMOTO, K.; KOYAMA, N. et al. Cryopreservation of mature bovine oocytes by vitrification in straws. Cryobiology, v.37, p.77-85, 1998.

PICKERING, S.J.; JOHNSON, M.H. The influence of cooling on the organization of the meiotic spindle of mouse oocyte. Human Reproduction, v.2, p.207-216, 1987.

SAALFELD, M.H.; RUMPF, R.; DESCHAMPS, J.C. et al. Vitrificação de ovócitos imaturos bovinos. Revista Brasileira de Reprodução Animal, v.21, n.2, p.75-78, 1997.

SAHA, S.; RAJAMAHENDRAN, R.; BOEDIONO, A. et al. Viability of bovine blastocysts obtained after 7,8 , or 9 days of culture in vitro fallowing vitrification and one-step rehydratation. Theriogenology, v.46, p.331-343, 1996.

SALUSTRI, A.; YANAGISHITA, M.; HASCALL, V.C. Mouse oocytes regulate hyaloronic acid synthesis and mucification by FSH-stimulated cumulus cells. Development of Biology, v.138, p.26-32, 1990.

SHAW, J.M.; ORANRATNACHAI, A.; TROUNSON, A.O. Fundamental cryobiology of mammalian oocytes and ovarian tissue. Theriogenology, v.53, p.59-72, 2000.

SIRARD, M.A.; BILODEAU, S. Granulosa cells inhibit the resumption of meiosis in bovine oocytes in vitro. Biology of Reproduction, v.43, n.5, p.777-783, 1990.

SUZUKI, T.; TAKAGI, M.; BOEDIONO, A. Calves obtained after transfer of frozen-thawed bovine immature oocytes cryopreserved in various cryoprotectants. Theriogenology, v.45, n.1, p.361, 1996.
THIBAULT, C.; SZÖLlÖSI, D.; GERARD, M. Mammalian oocytes maturation. Reproduction Nutrition and Development, v.27, p.865-896, 1987.

VAJTA, G. Criopreservação de ovócitos e embriões produzidos in vitro. Arquivos da Faculdade de Veterinária da UFRS, v.25, n.1, p.85-93, 2000b.

VAJTA, G. Vitrification of the oocytes and embryos of domestic animals. Animal of Reproduction Science, v.60-61, p.357364, 2000a.

Van BLERKOM, J. Maturation at high frequency of germinalvesicle-stage mouse oocytes after cryopreservation : alteration in citoplasmatic, nuclear, nucleolar and chromossomal structure and organization associated with vitrification. Human Reproduction, v.4, p.883-898, 1989.

Van DER, E.J.C.; NERINCKX, S.S.; Van STEIRTEGHEM, A.C. In vitro maturation of mouse germinal vesicle-stage oocytes following cooling, exposure to cryoprotectants and ultrarapid freezing: limited effect on the morphology of the second meiotic spindle. Human Reproduction, v.7, p.14401446, 1992.

VICENT, C.; PICKERING, S.J.; JOHNSON, M.H. The hardening effect of dimethyl sulphoxide on the mouse zona pellucida requires the presence of an oocyte and in associated with a reduction in the number of cortical granules present. Journal of Reproduction and Fertility, v.89, p.253-259, 1990.

WATANABE, Y.F., OLIVEIRA FILHO, E.B. Fecundação "in vitro" de oócitos bovinos criopreservados. In: REUNIÃO ANUAL DA SOCIEDADE BRASILEIRA DE TRANSFERÊNCIA DE EMBRIÕES, 7., 1992, Jaboticabal. Anais... Jaboticabal: 1992. p.100.

YANG, Q.Z.; SUN, Q.Y.; LIU, G.Y. Development competence and ultrastructure damage of cryopreserved G.V. stage bovine oocytes. Theriogenology, v.41, p.342, 1994.

YANG, C.B.; YANG, B.S.; SEONG, H.M. et al. Effects of vitrification methods and polivinilpirrolidone supplementation on the viability of immature bovine oocytes. Theriogenology, v.53, n.1, p.266, 2000.

Recebido em: 20/06/01 Aceito em: 08/03/02 